\title{
Prevalence of Class 1 Integron, Resistance Gene Cassettes and Antimicrobial Susceptibility Profiles among Isolates of Pseudomonas aeruginosa in Iran
}

\author{
Maryam Mirahsani, Ahmad Khorshidi*, Rezvan Moniri, Hamid Reza Gilasi \\ Department of Microbiology and Immunology, Faculty of Medicine, Kashan University of Medical Sciences, \\ Kashan, Iran \\ Email: "khorshidimalahmadi@gmail.com
}

Received 23 February 2016; accepted 21 June 2016; published 24 June 2016

Copyright (C) 2016 by authors and Scientific Research Publishing Inc.

This work is licensed under the Creative Commons Attribution International License (CC BY).

http://creativecommons.org/licenses/by/4.0/

(c) (i) Open Access

\begin{abstract}
Pseudomonas aeruginosa is one of the most important opportunistic human pathogens worldwide. High prevalence of Multi Drug Resistant $P$. aeruginosa (MDRPa) in Iran is a serious problem for antimicrobial therapy. Several studies have reported the MDRPa in Europe and Asia. Due to the use of broad-spectrum antibiotics, bacterial resistance is increasing in Iran, located in Middle East. The present cross-sectional study was designed to investigate the prevalence of class 1 integron, resistance gene cassettes and antimicrobial susceptibility profiles among isolates of $P$. aeruginosa in Al-Zahra Hospital, Isfahan City, central part of Iran from Jan-Sep 2014. The aim of this study was to determine the antimicrobial susceptibility, the prevalence of Class1 integron, resistance gene a measuring in Iran. A total of 231 P. aeruginosa isolates were collected from clinical specimens including urine $(50.6 \%)$, tracheal tube $(25.5 \%)$, wound $(13.4 \%)$, blood $(6.1 \%)$, catheter $(2.2 \%)$, cerebrospinal fluid $(1.7 \%)$ and sputum $(0.4 \%)$ isolates from hospitalized patients (mean age: $50.27 \pm$ 24.12 years).The majority of patients $(68 \%)$ were male. Isolates were collected from different parts of the hospital as follows: ICU, Internal Medicine, Emergency care, Pediatrics, Nephrology, Transplant Center, General surgery and Infectious. Revealed data show a high rate of MDR $P$. aeruginosa isolates in the studied area; also, the result signifies the spread of aadA6 among clinical isolates in hospitalized patients.
\end{abstract}

\section{Keywords}

Pseudomonas aeruginosa, Resistance Gene Cassettes, Antibiotic Susceptibility

\footnotetext{
${ }^{*}$ Corresponding author.
}

How to cite this paper: Mirahsani, M., Khorshidi, A., Moniri, R. and Gilasi, H.R. (2016) Prevalence of Class 1 Integron, Resistance Gene Cassettes and Antimicrobial Susceptibility Profiles among Isolates of Pseudomonas aeruginosa in Iran. Open Journal of Medical Microbiology, 6, 87-96. http://dx.doi.org/10.4236/ojmm.2016.62012 


\section{Introduction}

Pseudomonas aeruginosa is one of the most important opportunistic human pathogens responsible for $10 \%-15 \%$ of the nosocomial infections worldwide [1] [2]. This pathogen is naturally resistant to various antimicrobial agents, and also it has a distinctive valence through multiple mechanisms to become resistant to almost all the commercial antibiotics [3] [4]. High prevalence of Multi Drug Resistant (MDR) P. aeruginosa in Iran is a serious problem for antimicrobial therapy [5]-[10]. Infections caused by aforementioned drug resistant pathogens are dependent with notable increase in morbidity and mortality [7].

Plasmids, transposons and integrons are mobile genetic elements that they resort of earning resistance mechanisms cooperating to $P$. aeruginosa multidrug resistance [9]. The integron is potentially a major element in the spreading of multidrug resistance among gram-negative bacteria, particularly in genus Pseudomonas [4]. Integrons are one of the genetic elements have been found to be able to elevate absorption and expression of drug resistance genes located within gene cassettes [10]-[12]. Out of all sequenced bacterial genomes, integrons have been found in approximately 9\% [11]. Various investigations revealed the presence of class 1 integron in $40 \%$ $70 \%$ of gram-negativepathogens isolated from clinical setting. It is obvious that integrons have major antibiotic resistance roles, causing difficulties in bacterial infection control; so, it is important to understand the origin of these elements for exploring the means by which bacterial lateral gene transfer can seriously impact on, and be impacted by, human activities and for practical control of antibiotic resistance [11]-[19]. Class 1 itegron is made of a functional platform (5'CS), which contains the integrase gene (intI), the recombination site (attI) and a promoter region (P ant), and a (3'CS), which normally includes the qacED1and sulI genes [6]-[24]. The gene cassettes among integrons are variable in these structures, small, mobilegenetic elements, containing of a single gene (or sporadically two genes) in addition a recombination site named the 59-be [24]-[31]. Several resistance gene cassettes carried by class 1 integrons in $P$. aeruginosa encodes multiple resistance mechanisms such as resistance to beta-lactams, aminoglycosides and other antimicrobial agents [9]-[13]. Several studies have reported the multiple drug resistance in P. aeruginosa clinical strains in European and Asian countries [26] [27]. Due to the use of broad-spectrum antibiotics, bacterial resistance is increasing in Iran, bordered with European and Asian countries. The present study was designed to investigate the prevalence of class 1 integron, resistance gene cassettes and antimicrobial susceptibility profiles among isolates of P. aeruginosa in Al-Zahra Hospital, Isfahan City, central part of Iran.

\section{Methodology}

\subsection{Bacterial Isolates}

A cross-sectional study was conducted in Al-Zahra Hospital in Isfahan City, located in central part of Iran from Jan-Sep 2014. Two hundred and thirty one P. aeruginosa strains were obtained from different specimens of inpatients coming from clinical cases, including 117 urine (50.6\%), 59 tracheal tube (25.5\%), 31 wound (13.4\%), 14 blood (6.1\%), 5 catheter (2.2\%), 4 cerebrospinal fluid (1.7\%) and 1 sputum $(0.4 \%)$ isolates. These samples were collected from different parts of the hospital as follows: ICU ${ }^{1}$, Internal Medicine, Emergency care, Pediatrics, Nephrology, Transplant Center, General surgery and Infectious.

At first, primary isolation was performed by phenotypic characteristics on blood agar and McConkey(Merck, Germany), then the isolates identification was carried out and confirmed to the species level by standard biochemical tests including Gram stain, catalase and oxidase test, O/F (Oxidation Fermentation) test (Merck, Germany), pyocyanin pigment production and growth at $42^{\circ} \mathrm{C}$ [8].

\subsection{Antimicrobial Susceptibility Test}

Antimicrobial susceptibility test was performed on isolates using the Kirby-Bauer disk-diffusion breakpoint assay on Mueller-Hinton agar (Merck, Germany); and the cultures were incubated for $24 \mathrm{~h}$ at $37^{\circ} \mathrm{C}$. The following antibiotic disks (Mast, Bootle, Merseyside, UK) were used for susceptibility test: imipenem (10 $\mu \mathrm{g})$, meropenem $(10 \mu \mathrm{g})$ aztreonam $(30 \mu \mathrm{g})$, cefepime $(30 \mu \mathrm{g})$, ceftazidime $(30 \mu \mathrm{g})$, amikacin $(30 \mu \mathrm{g})$, gentamicin $(10 \mu \mathrm{g})$, ciprofloxacin $(5 \mu \mathrm{g})$, norfloxacin $(10 \mu \mathrm{g})$, t obramycin $(30 \mu \mathrm{g})$, piperacillin/tazobactam $(100 / 10 \mu \mathrm{g})$ and colistin $(10$ $\mu \mathrm{g}$ ). Pseudomonas aeruginosa (ATCC 27853) and Escherichia coli (ATCC 25922) were used as the quality

\footnotetext{
${ }^{1}$ Intensive care unit (ICU).
} 
control strains in every susceptibility test [12]. MDR was defined as non-susceptible to at least one agent in three or more anti-pseudomonal antimicrobial categories, and as extensively drug- resistant $P$. aeruginosa (XDR-PA) if it was non-susceptible to at least one agent in all but two or less anti-pseudomonal antimicrobial categories.

\subsection{DNA Extraction and PCR Amplification}

DNA extraction was carried out on MDR P. aeruginosa by boiling method. The template DNA stored at $-20^{\circ} \mathrm{C}$ until polymerase chain reaction (PCR) amplification was performed.MDR P. aeruginosa isolates were screened for the presence of class 1 integron by using 4 specific primers located on intI1 gene, qacED, sulI and gene cassette regions. Master mix component was as follow: 10× PCR buffer in a final concentration of $1 \times$, MgCl2 (50 $\mathrm{mM}$ ) in a final concentration of $1.5 \mathrm{mM}, 10 \mathrm{mM}$ dNTPs Mix in a final concentration of $0.2 \mathrm{mM}$, Forward and Reverse primers in a final concentration of $0.4 \mu \mathrm{M}$. PCR amplification was performed in a total volume of $25 \mu \mathrm{l}$ ( $24 \mu \mathrm{l}$ of PCR master mix plus $1 \mu \mathrm{l}$ of template DNA). Amplification was carried out in a thermocycler (Eppendorf Master cyclers, MA) using the published paper programs [6] [7]: The primers (obtained from Takapouzist Company, Iran) used for the analysis and PCR conditions are summarized in Table 1. Class1 integron variable regions were amplified using primers Int1, In5'cs and In3'cs (Table 1). After performing PCR reaction, amplification products were identified using $1.5 \%$ agarose gel electrophoresis stained with $0.5 \mu \mathrm{g} / \mathrm{ml}$ ethidium bromide solution. Then, the results visualized using UV trans-illuminator on the UV gel document (Ingenius, Syngene). The size of specific bands was compared with 100 bp DNA ladder (Bioneer, Korea).

\subsection{DNA Sequencing and Sequence Analysis}

Sequencing was done by Sanger's method (Applied Biosystems 3730/3730xl DNA Analyzers Sequencing; Bioneer). The sequences were analyzed using Chromas Pro version 1.7.5 Technelysium

(http://www.technelysium.com.au/). Nucleotide sequences were compared using online BLAST software (http://www.ncbi.nlm.nih). The sequences obtained from the gene cassette analysis have been deposited in GenBank under accession numbers FJ908755 for aadB, FJ908756 for aadA6 and orfDgenes, KJ679405 for aacA7, bla $_{O X A-2}$, aacA8 and HF546976 for bla $_{N D M-1}$ gene.

\section{Results}

The mean age of the studied patients was $50.27 \pm 24.12$ years, which ranged from under one to 91 years. Demographic information of patients in this study has been summarized in Table 2. The majority of patients (68\%) were male, 157 versus 74 females. The number and rate of isolates from different parts of the hospital were as follows: ICU, 71 (30.7\%); Internal Medicine, 38 (16.5\%); Emergency care, 14 (6.1\%); Pediatrics, 17 (7.3\%); Nephrology, 9(3.9 \%); Transplant Center, 28 (12.1\%); General Surgery, 49 (21.2\%) and Infectious, 5 (2.2\%).

\subsection{Antimicrobial Resistance Pattern}

The resistance pattern of $P$. aeruginosa isolates in this study revealed that 192 (83.1\%) were Multi Drug Resis-

Table 1. Primer sets and PCR conditions used in this study.

\begin{tabular}{|c|c|c|c|c|}
\hline Primer & Sequence $\left(5^{\prime} \rightarrow 3^{\prime}\right)$ & PCR conditions & PCR product (bp) & Reference \\
\hline $\begin{array}{l}\text { IntI } \mathrm{f} \\
\text { IntI } \mathrm{r}\end{array}$ & $\begin{array}{l}\text { AAA ACC GCC ACT GCG CCG TTA } \\
\text { GAA GAC GGC TGC ACT GAA CG }\end{array}$ & $\begin{array}{c}94^{\circ} \mathrm{C}, 30 \mathrm{~s} ; 55^{\circ} \mathrm{C}, 30 \mathrm{~s} ; 72^{\circ} \mathrm{C}, \\
1 \mathrm{~min}(35 \text { cycles })\end{array}$ & This work & 6 \\
\hline $\begin{array}{l}\text { qacED1-f } \\
\text { qacED1-r }\end{array}$ & $\begin{array}{l}\text { ATCGCAATAGTTGGCGAAGT } \\
\text { CAAGCTTTTGCCCATGAAGC }\end{array}$ & $\begin{array}{c}94^{\circ} \mathrm{C}, 1 \mathrm{~min} ; 48^{\circ} \mathrm{C}, 45 \mathrm{~s} ; 72^{\circ} \mathrm{C} \text {, } \\
1 \mathrm{~min}(35 \text { cycles })\end{array}$ & 236 & 7 \\
\hline $\begin{array}{l}\text { SulI-f } \\
\text { SulI-r }\end{array}$ & $\begin{array}{l}\text { CTTCGATGAGAGCCGGCGGC } \\
\text { GCAAGGCGGAAACCCGCGCC }\end{array}$ & $\begin{array}{c}94^{\circ} \mathrm{C}, 1 \mathrm{~min} ; 48^{\circ} \mathrm{C}, 45 \mathrm{~s} ; 72^{\circ} \mathrm{C} \text {, } \\
1 \mathrm{~min}(35 \text { cycles })\end{array}$ & 437 & 7 \\
\hline $\begin{array}{l}\text { In5'CS } \\
\text { In3'CS }\end{array}$ & $\begin{array}{l}\text { GGCATCCAAGCAGCAAG } \\
\text { AAGCAGACTTGACCTGA }\end{array}$ & $\begin{array}{c}94^{\circ} \mathrm{C}, 1 \mathrm{~min} ; 48^{\circ} \mathrm{C}, 45 \mathrm{~s} ; 72^{\circ} \mathrm{C} \text {, } \\
1 \mathrm{~min}(35 \text { cycles })\end{array}$ & Variable & 7 \\
\hline
\end{tabular}


Table 2. Factors associated with class 1 integron among Pseudomonas aeruginosa isolates.

\begin{tabular}{|c|c|c|c|}
\hline Patient characteristic & $\begin{array}{l}\text { IntI positive } \mathrm{n}(\%) \\
\mathbf{N}=146(\mathbf{6 3 . 2})\end{array}$ & $\begin{array}{c}\text { IntI negative n (\%) } \\
\mathbf{N}=85 \text { (36.8) }\end{array}$ & $P$ value \\
\hline \multicolumn{4}{|l|}{ Age } \\
\hline$<40$ Years & $33(43.4 \%)$ & $43(56.6 \%)$ & $<0.001$ \\
\hline$\geq 40$ Years & $113(72.9 \%)$ & $42(27.1 \%)$ & \\
\hline \multicolumn{4}{|l|}{ Sex } \\
\hline Male & $102(65 \%)$ & 55 (35\%) & \\
\hline Female & 44 (59.5\%) & 30 (40.5\%) & \\
\hline \multicolumn{4}{|l|}{ Ward } \\
\hline Transplant center & $28(96.6 \%)$ & $1(3.4 \%)$ & $<0.001$ \\
\hline ICU & $48(67.6 \%)$ & $23(32.4 \%)$ & \\
\hline Internal medicine & $20(52.6 \%)$ & $18(47.4 \%)$ & \\
\hline Infectious & $3(60 \%)$ & $2(40 \%)$ & \\
\hline General surgery & $26(53.1 \%)$ & 23 (46.9\%) & \\
\hline Paediatrics & $4(25 \%)$ & $12(75 \%)$ & 0.02 \\
\hline Emergency & $10(71.4 \%)$ & $4(28.6 \%)$ & \\
\hline Nephrology & $7(77.8 \%)$ & $2(22.2 \%)$ & \\
\hline \multicolumn{4}{|l|}{ Sample type } \\
\hline Urine & $83(70.9 \%)$ & $34(29.1 \%)$ & 0.01 \\
\hline Catheters & $3(60 \%)$ & $2(40 \%)$ & \\
\hline Blood & $6(42.9 \%)$ & $8(57.1 \%)$ & \\
\hline Wound & 17 (54.8\%) & $14(45.2 \%)$ & \\
\hline Tracheal tube & 35 (59.3\%) & $24(40.7 \%)$ & \\
\hline CSF & $1(25 \%)$ & $3(75 \%)$ & \\
\hline Sputum & $1(100 \%)$ & $0(0 \%)$ & \\
\hline \multicolumn{4}{|l|}{ Drug resistance } \\
\hline Multi drug-resistance & $146(76 \%)$ & $46(24 \%)$ & $<0.001$ \\
\hline Extensively-drug resistance & $78(88.6 \%)$ & $10(11.4 \%)$ & $<0.001$ \\
\hline
\end{tabular}

tant (MDR). Eighty (38.1\%) P. aeruginosa isolates were resistant to all antibioticstested in this study. Resistanceor intermediate resistance (non-susceptible) was mostly observed toimipenem (63.6\%), meropenem (63.6\%), gentamicin (81.4\%), amikacin (69.7\%), ceftazidime (61.9\%),ciprofloxacin $(69.7 \%)$, tobramycin $(74.5 \%)$, cefepime (61.9\%), norfloxacin (68.4\%), aztreonam (60.6\%), colistin (58.9\%) and piperacillin-tazo- bactam (56.7\%) (Figure 1).

\subsection{Detection and Characterization of Integrons}

PCR assay was performed to detect integrin integrase genes (intI1), qacED, and sulI genes, and gene cassette regions (5CS/3CS) among 192 clinical MDR P. aeruginosa isolates. Out of 192 isolates, 146 (76\%) were positive for class 1 integron by amplifying the intI1 gene. Nucleotide sequence analysis of the class 1 integron variable regions revealed the presence of 3 different fragment sizes of approximately 0.8, 1.2 and $2.5 \mathrm{~kb}$ (Figure 2). 120 


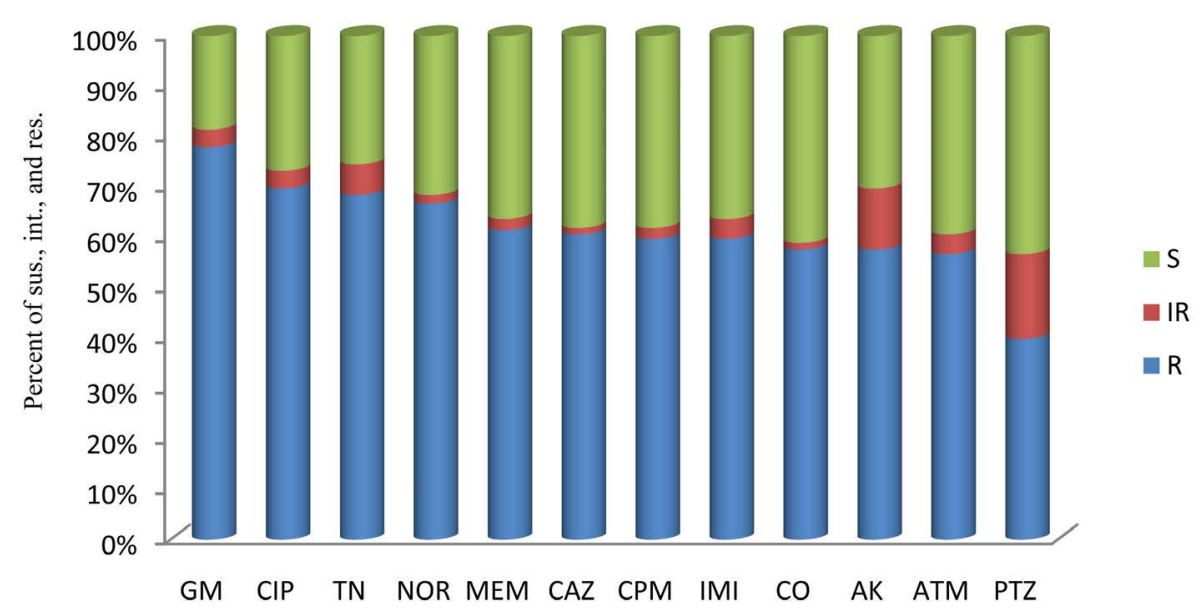

Figure 1. The percentage rate of antibiotic resistance of 192 MDR P. aeruginosa isolates from hospitalized patients in Alzahra Hospital in Isfahan, Iran. GM: gentamicin; CIP: ciprofloxacin; TN: tobramycin; NOR: norfloxacin; CAZ: ceftazidime; CPM: cefepime; IMI: imipenem; MEM: meropenem; Co: colistin; Ak: amikacin; ATM: aztreonam; PTZ: Piperacillin-tazobactam. S: sensitive; IR: intermediate; $\mathrm{R}$ : resistant.

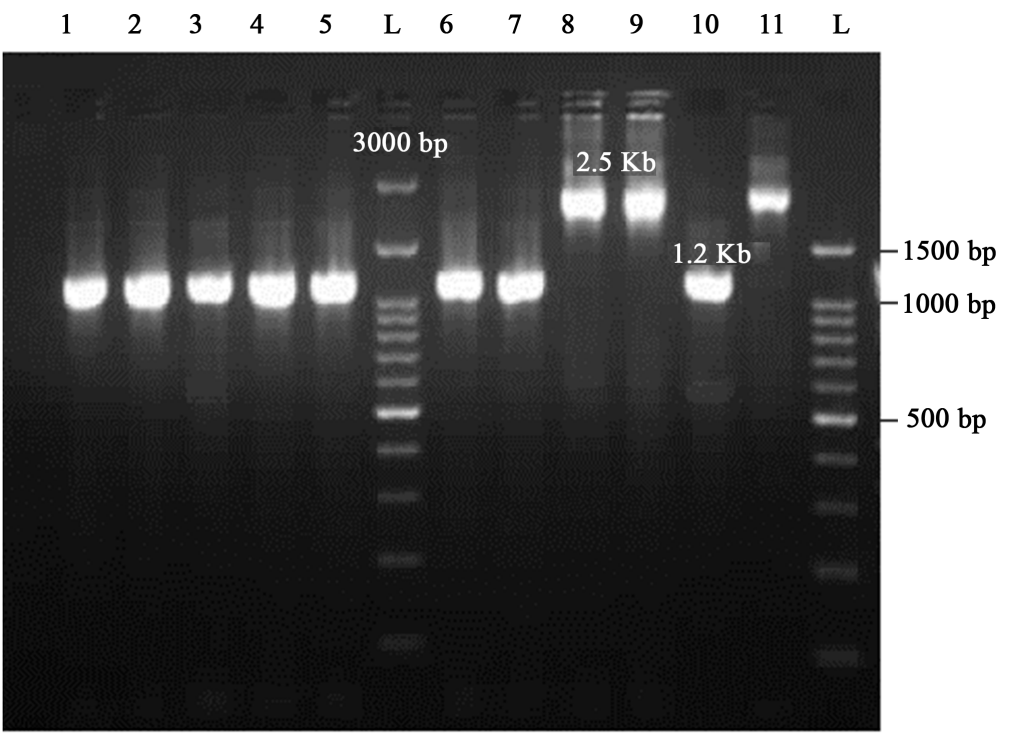

Figure 2. PCR amplification products of class 1 integron variable regions using primers In5' and In3' CS. L: 100 bp DNA ladder (Bioneer, Korea); lanes 1- 11, integron profiles 1 - 11 respectively among 192 MDR P. aeruginosa isolates in Al-Zahra Hospital in Isfahan, Iran.

isolates (62.5\%) carried class 1 integron with sizes of approximately $1.2 \mathrm{~kb}$, twenty three isolates (12\%) with sizes of approximately $2.5 \mathrm{~kb}$ and three isolate (1.5) with sizes of approximately $0.8 \mathrm{~kb}$.

The isolation sites and samples found in this study have been summarized in Table 3; also, the percentage rate of antibiotic resistance and presence of class 1 integrons among 192 MDR P. aeruginosa strains isolated from patients hospitalized in this study has been summarized in Table 4, Figure 1 and Figure 3.

\section{Discussion}

Multi Drug Resistant $P$. aeruginosa is a serious challenge for treatment of nosocomial contagion, and a suitable antibiotic choice to initiate remedy is necessary for optimizing the clinical consequence [17]. As the results revealed, the most of isolates were resistant to several antimicrobial agents tested in this investigation and most of prevalence of class 1 integrons found in $P$. aeruginosa isolates consistent with those previously reported from 


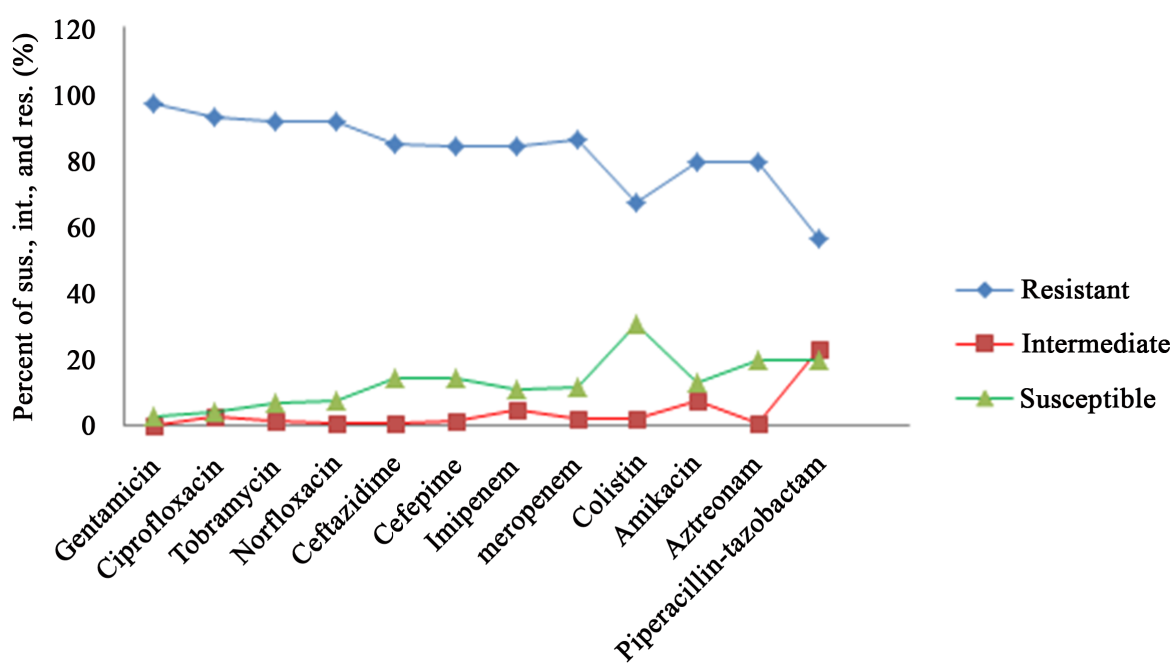

Figure 3. The percentage rate of antibiotic resistance and presence of class 1 integrons among 192 MDR P. aeruginosa isolates from hospitalized patients in Al-Zahra Hospital in Isfahan, Iran.

Table 3. Distribution of Pseudomonas aeruginosa isolates according to hospitals wards and sample types.

\begin{tabular}{ccccccccc} 
& $\begin{array}{c}\text { ICU } \\
\text { (No) }\end{array}$ & $\begin{array}{c}\text { Transplant } \\
\text { center (No) }\end{array}$ & $\begin{array}{c}\text { Nephrology } \\
\text { (No) }\end{array}$ & $\begin{array}{c}\text { General } \\
\text { surgery (No) }\end{array}$ & $\begin{array}{c}\text { Emergency } \\
\text { care (No) }\end{array}$ & $\begin{array}{c}\text { Infectious } \\
\text { (No) }\end{array}$ & $\begin{array}{c}\text { Internal } \\
\text { medicine (No) }\end{array}$ & $\begin{array}{c}\text { Paediatrics } \\
\text { (No) }\end{array}$ \\
\hline Urine & 24 & 23 & 9 & 24 & 12 & 2 & 18 & 5 \\
Tracheal tube & 39 & 0 & 0 & 3 & 0 & 2 & 11 & 4 \\
Blood & 4 & 2 & 0 & 4 & 0 & 1 & 3 & 0 \\
Wound & 1 & 2 & 0 & 15 & 2 & 0 & 6 & 5 \\
Catheter & 3 & 0 & 0 & 0 & 0 & 0 & 0 & 2 \\
Sputum & 0 & 1 & 0 & 0 & 0 & 0 & 0 & 0 \\
CSF & 0 & 0 & 0 & 3 & 0 & 0 & 0 & 1 \\
Total & 71 & 28 & 9 & 49 & 14 & 5 & 38 & 17 \\
\hline
\end{tabular}

Table 4. The percentage rate of antibiotic resistance of class 1 integrons positive isolates among 192 MDR P. aeruginosa types.

\begin{tabular}{cccc}
\hline & Resistance No. (\%) & Intermediate No. (\%) & Sensitive No. (\%) \\
\hline Gentamicin & 97.3 & 0 & 2.7 \\
Ciprofloxacin & 93.2 & 2.7 & 4.1 \\
Tobramycin & 91.8 & 1.4 & 6.8 \\
Norfloxacin & 91.8 & 0.7 & 7.5 \\
Ceftazidime & 84.9 & 0.7 & 14.4 \\
Cefepime & 84.2 & 1.4 & 14.4 \\
Imipenem & 84.2 & 4.8 & 11 \\
Meropenem & 86.3 & 2.1 & 11.6 \\
Colistin & 67.1 & 2.1 & 30.8 \\
Amikacin & 79.5 & 7.5 & 13 \\
Aztreonam & 79.5 & 0.7 & 19.9 \\
Piperacillin-tazobactam & 56.8 & 23.3 & 19.9 \\
\hline
\end{tabular}


Iran [1]-[21]. The high spread of MDRP. aeruginosa has become serious challenge in clinical settings. 192 isolates (83.1\%) were considered as MDRPa (Multi Drug Resistant $P$. aeruginosa) which may lead to problems in treatment of $P$. aeruginosa infection. The special high rate of MDRPa found in this work could be due to the repeated and unsuitable use of antibiotics in Iran. The results of the present study indicated that the frequency of MDRPa was $83.1 \%$; also, 88 (38.1\%) isolates of $P$. aeruginosa were resistant to all the classes of antibiotics tested as well as strong relevancy intense was observed between integron presence and multiresistance.

The results of the present investigation showed thatthe screening for integrons in $P$. aeruginosa clinical isolates (192 MR and 39 Non-MR) from the Al-Zahra hospital; and146/231 isolates carry class 1 integrons. Out of these 192 MR isolates, 146 (76\%) were positive for the presence of class 1 integrons. Several reports have revealed the presence of aminoglycoside resistance genes associated with integrons found in gram-negative bacteria [14]-[16] and also the present study revealed that aminoglycoside resistance was spread more than in the majority of isolates, including those of integron-positive. According to results, a significant difference was shown in distribution and frequency of class 1 integrons among MR and non-MR clinical strains of $P$. aeruginosa from Al-Zahra hospital, since only MR isolates (48.4\%) harboured class 1 integrons carrying gene cassettes $(\mathrm{P}<0.001)$. Among MDR isolates, $146(76 \%)$ showed class 1 integrons. The rate of class 1 integrons observed in this study is higher than previously reported rates of 57.4\% from Nigeria [9], 41.5\% from Brazil [6], 45.8\% from patients in southern china [4], 82\% from Thai hospital in Thailand [7] and 69.2\% from burn patients in Guilan, Iran [10]. In the current study a notable relevance was found between the presence of integrons and resistance against gentamicin, amikacin, imipenem, meropenem, ceftazidime, cefepime, tobramycin, norfloxacin, aztreonam and ciprofloxacin $(\mathrm{P}<0.001)$.

The high resistance level against aminoglycoside antibiotics (gentamicin, amikacin and tobramycin) was observed in this study. Resistance to this class of antibiotics in P. aeruginosa is usually associated with the production of aminoglycoside adenylyltransferase which leads to resistance to aforementioned antibiotics [12]. Class 1 integrons have been dependent with different antibiotic resistance genes and organized important role in the expansion of antimicrobial resistance [7].

High resistance among $P$. aeruginosa strains against the following antibiotics: gentamicin, ciprofloxacin, tobramycin, norfloxacin, ceftazidime, cefepime, imipenem, meropenem, amikacin, aztreonam isolated from sputum, tracheal tube, urine and wounds was observed. The resistance rate of $P$. aeruginosa isolates from sputum, tracheal tube, urine, wound, blood, catheter andcerebrospinal fluid was reported as $100 \%, 89.8 \%, 83.8 \%, 80.6 \%$, $64.3 \%, 60 \%$ and $50 \%$ respectively. In the present study, piperacillin/tazobactam and colistin was the most efficient antibiotics against $P$. aeruginosa and the antibiotic susceptibility test results showed $43.3 \%$ susceptible to piperacillin-tazobactam and $41.1 \%$ susceptible to colistin compared with other studies carried out on $P$. aeruginosa isolated from burn patients in Tehran in which reported $87.2 \%$ resistance to piperacillin-tazobactam [5]. This investigation reports 93 (48.4\%) P. aeruginosa isolates containing class1 integron carrying resistance gene cassettes. Variable region genes of class 1 integrons found in our isolates were as follows: aadB gene (about 0.8 $\mathrm{kb}$ ), aadA6, orfD (about $1.2 \mathrm{~kb}$ ) and aacA7, aacA8, bla $a_{\text {oxa } 2}$, bla $_{N D M-1}$ gene (about $2.5 \mathrm{~kb}$ ) and 120 clinical isolate have an aadA6-orfD array (about $1.2 \mathrm{~kb}$ ). The aadA6-orfD had the maximum gene cassette in this investigation as well as the most prevalent gene cassette array in P. aeruginosa in Thai hospital in Thailand [7].

Genes giving resistance to aminoglycosides and $\beta$-lactams are frequently found in integrons from $P$. aeruginosa isolates and the most popular aminoglycoside resistance gene cassettes related to aad and aac families [15]-[17]. The first report of identification and sequencing of a streptomycin/spectinomycinadenylyl transferase gene (aadA) was carried out in Escherichia coliand recently the crystal structure of an aminoglycoside adenylyl transferase (AadA) has been reported [22]. Aminoglycosides are a relatively large class of antibiotics and AAC (3)-II determines resistance to gentamicin, tobramycin and netilmicin [30]; also, AAC(6')-II determines resistance to netilmicin, gentamicin and tobramycin. AAC(3)-I determines resistance to gentamicin and AAC(6')-I determines resistance to tobramycin, netilmicin and amikacin. Finally, ANT (2')-I determines resistance to gentamicin and tobramycin [31] [32].

This is noticeable that orfD has unknown functions and can potentially translate as a polypeptide chain. An ORF (open reading frame) is a portion of a DNA molecule that contains no stop codons, when translated into amino acids [25]. Twenty three of 192 (12\%) clinical isolates have aacA7, aacA8, bla $a_{\text {oxa } 2}, b a_{N D M-1}(2.5 \mathrm{~kb})$. $b l a_{0 \times a 2}$ belongs to class $\mathrm{D}$ extendeds pectrum b-lactamases and hydrolyzes b-lactam antibiotics such as ceftazidime.

Class $\mathrm{D} \beta$-lactamases (oxacillinases) (OXA type enzymes) belongs to functional group $2 \mathrm{~d}$ and molecular class 
D [29]. OXA-1, OXA-2 and OXA-10 enzymes determine resistance to ureidopenicillins and carboxypenicillins but not to ceftazidime. Resistance, resulting from production of piperacillin and ticarcillin OXA-2 enzymes is lower than the resistance that develops when OXA-10 and OXA-1 oxacillinases are produced [29].

Study done among clinical isolates of Pseudomonas aeruginosa in 5hospitals Iran, Tehran reported class 1 integron containing aadB, aadA6-orfD, aacA4 and $b a_{o x a 10}$ [13]. Another study on gene cassette of Class 1 integrons in $P$. aeruginosa isolates from clinical settings in Amazon region, Brazil shoed that the most frequent gene cassette found was from the aacA family [6]. These our data indicate that $b l a_{N D M-1}$ gene is the first report among class 1 integrons found in $P$. aeruginosa isolates from clinical settings in Iran.A member of a large gene family that encodes beta-lactamase enzymes called carbapenemases is NDM-1 gene [23].

\section{Conclusion}

In conclusion, our data show that high rate resistant to multiple drugs among $P$. aeruginosa signifies the spreads of aadA6 among clinical isolates in hospitalized patients in Al-Zahra hospital. There is a significant relationship to antibiotic resistance and class 1 integron and mobile genetic elements play a major role in the development of a resistance gene.

\section{Acknowledgements}

This study was approved by the Kashan University of Medical Sciences Ethics Committee, Kashan, Iran. We thank the Research council of Kashan University of Medical Sciences for supporting this project; we would like to thank the personnel of the Al-Zahra Hospital in Isfahan, Iran for their co-operation.

\section{References}

[1] Fazeli, H., Sadighian, H., Esfahani, B.N. and Pourmand, M.R. (2013) Identification of Class-1 Integron and Various $B$ Lactamase Classes among Clinical Isolates of Pseudomonas aeruginosa at Children's Medical Center Hospital. Journal of Medical Bacteriology, 1, 25-36.

[2] Strateva, T. and Yordanov, D. (2009) Pseudomonas Aeruginosa-A Phenomenon of Bacterial Resistance. Journal of Medical Microbiology, 589, 1133-1148. http://dx.doi.org/10.1099/jmm.0.009142-0

[3] Kobayashi, K., Hayashi, I., Kouda, S., Kato, F., Fujiwara, T., Kayama, S., et al. (2013) Identification and Characterization of a Novel Aac $\left(6^{\prime}\right)$-Iag Associated with the blaIMP-1-Integron in a Multidrug-Resistant Pseudomonas aeruginosa. PloS ONE, 8, e70557.

[4] Xu, Z., Li, L., Shirtliff, M.E., Alam, M., Yamasaki, S. and Shi, L. (2009) Occurrence and Characteristics of Class 1 and 2 Integrons in Pseudomonas aeruginosa Isolates from Patients in Southern China. Journal of Clinical Microbiology, 47, 230-234. http://dx.doi.org/10.1128/JCM.02027-08

[5] Moazami-Goudarzi, S. and Eftekhar, F. (2013) Assessment of Carbapenem Susceptibility and Multidrug-Resistance in Pseudomonas aeruginosa Burn Isolates in Tehran. Jundishapur Journal of Microbiology, 6, 162-165.

[6] Fonseca, É.L., Vieira, V.V., Cipriano, R. and Vicente, A.C. (2005) Class 1 Integrons in Pseudomonas aeruginosa Isolates from Clinical Settings in Amazon Region, Brazil. FEMS Immunology and Medical Microbiology, 44, 303-309. http://dx.doi.org/10.1016/j.femsim.2005.01.004

[7] Kiddee, A., Henghiranyawong, K., Yimsabai, J., Tiloklurs, M. and Niumsup, P.R. (2013) Nosocomial Spread of Class 1 Integron-Carrying Extensively Drug-Resistant Pseudomonas aeruginosa Isolates in a Thai Hospital. International Journal of Antimicrobial Agents, 42, 301-306.

[8] Hall, G.S. (2007) Nonfermenting and Miscellaneous Gram Negative Bacilli. In: Mahon, C.R., Lehman, D.C. and Manuselis, G., Eds., Textbook of Diagnostic Microbiology, 3rd Edition, Saunders-Elsevier, Ohio, 564-584.

[9] Odumosu, B.T., Adeniyi, B.A. and Chandra, R. (2013) Analysis of Integrons and Associated Gene Cassettes in Clinical Isolates of Multidrug Resistant Pseudomonas aeruginosa from Southwest Nigeria. Annals of Clinical Microbiology and Antimicrobials, 12, 21-29. http://dx.doi.org/10.1186/1476-0711-12-29

[10] Nikokar, I., Tishayar, A., Flakiyan, Z., Alijani, K., Rehana-Banisaeed, S., Hossinpour, M., et al. (2013) Antibiotic Resistance and Frequency of Class 1 Integrons among Pseudomonas aeruginosa, Isolated from Burn Patients in Guilan, Iran. Iranian Journal of Microbiology, 5, 36-41.

[11] Gillings, M., Boucher, Y., Labbate, M., Holmes, A., Krishnan, S., Holley, M., et al. (2008) The Evolution of Class 1 Integrons and the Rise of Antibiotic Resistance. Journal of Bacteriology, 190, 5095-5100. http://dx.doi.org/10.1128/JB.00152-08 
[12] Chen, J., Su, Z., Liu, Y., Wang, S., Dai, X., Li, Y., et al. (2009) Identification and Characterization of Class 1 Integrons among Pseudomonas aeruginosa Isolates from Patients in Zhenjiang, China. International Journal of Infectious Diseases, 13, 717-721. http://dx.doi.org/10.1016/j.ijid.2008.11.014

[13] Shahcheraghi, F., Badmasti, F. and Feizabadi, M.M. (2010) Molecular Characterization of Class 1 Integrons in MDR Pseudomonas aeruginosa Isolated from Clinical Settings in Iran, Tehran. FFEMS Immunology and Medical Microbiology, 58, 421-425. http://dx.doi.org/10.1111/j.1574-695X.2009.00636.x

[14] Severino, P. and Magalhães, V.D. (2002) The Role of Integrons in the Dissemination of Antibiotic Resistance among Clinical Isolates of Pseudomonas aeruginosa from an Intensive Care Unit in Brazil. Research in Microbiology, 153, 221-226. http://dx.doi.org/10.1016/S0923-2508(02)01310-4

[15] Recchia, G.D. and Hall, R.M. (1995) Gene Cassettes: A New Class of Mobile Element. Microbiology, 141, $3015-3027$. http://dx.doi.org/10.1099/13500872-141-12-3015

[16] Fluit, A.C. and Schmitz, F.J. (2004) Resistance Integrons and Super-Integrons. Clinical Microbiology and Infection, 10, 272-288. http://dx.doi.org/10.1111/j.1198-743X.2004.00858.x

[17] Lister, P.D., Wolter, D.J. and Hanson, N.D. (2009) Antibacterial-Resistant Pseudomonas aeruginosa: Clinical Impact and Complex Regulation of Chromosomally Encoded Resistance Mechanisms. Clinical Microbiology Reviews, 22, 582-610. http://dx.doi.org/10.1128/cmr.00040-09

[18] Clinical and Laboratory Standards Institute (2006) 15. Performance Standards for Antimicrobial Testing. 16th Informational Supplement. M100-S16, CLSI, Wayne.

[19] Deng, Y., Bao, X., Ji, L., Chen, L., Liu, J., Miao, J., et al. (2015) Resistance Integrons: Class 1, 2 and 3 Integrons. Annals of Clinical Microbiology and Antimicrobials, 14, 45. http://dx.doi.org/10.1186/s12941-015-0100-6

[20] Stalder, T., Barraud, O., Casellas, M., Dagot, C. and Ploy, M.-C. (2012) Integron Involvement in Environmental Spread of Antibiotic Resistance. Frontiers in Microbiology, 3, 1-14. http://dx.doi.org/10.3389/fmicb.2012.00119

[21] Rajabnia, R., Asgharpour, F., Shahandashti, E.F., Khalilian, M., Norkhomami, S., Shafii, M., et al. (2013) Class 1 Integron in Pseudomonas aeruginosa Isolates from Different Places and Devices of ICU in Babol, Iran. Jundishapur Journal of Microbiology, 6, 138-143. http://dx.doi.org/10.5812/jjm.4850

[22] Papadovasilaki, M., Oberthür, D., Gessmann, R., Sarrou, I., Betzel, C., Scoulica, E., et al. (2015) Biophysical and Enzymatic Properties of Aminoglycoside Adenylyltransferase AadA6 from Pseudomonas aeruginosa. Biochemistry and Biophysics Reports, 4, 152-157. http://dx.doi.org/10.1016/j.bbrep.2015.09.011

[23] Kumarasamy, K.K., Toleman, M.A., Walsh, T.R., Bagaria, J., Butt, F., Balakrishnan, R., et al. (2010) Emergence of a New Antibiotic Resistance Mechanism in India, Pakistan, and the UK: A Molecular, Biological, and Epidemiological Study. The Lancet Infectious Diseases, 10, 597-602. http://dx.doi.org/10.1016/S1473-3099(10)70143-2

[24] Stokes, H.W. and Hall, R.M. (1989) A Novel Family of Potentially Mobile DNA Elements Encoding Site-Specific Gene-Integration Functions: Integrons. Molecular Microbiology, 3, 1669-1683. http://dx.doi.org/10.1111/j.1365-2958.1989.tb00153.x

[25] Stein, L.D. (2003) Integrating Biological Databases. Nature Reviews Genetics, 4, 337-345. http://dx.doi.org/10.1038/nrg1065

[26] Martinez-Freijo, P., Fluit, A.C., Schmitz, F.J., Grek, V.S.C., Verhoef, J. and Jones, M.E. (1998) Class I Integrons in Gram-Negative Isolates from Different European Hospitals and Association with Decreased Susceptibility to Multiple Antibiotic Compounds. Journal of Antimicrobial Chemotherapy, 42, 689-696. http://dx.doi.org/10.1093/jac/42.6.689

[27] Mathai, E., Grape, M. and Kronvall, G. (2004) Integrons and Multidrug Resistance among Escherichia coli Causing Community Acquired Urinary Tract Infection in Southern India. Acta Pathologica, Microbiologica, et Immunologica Scandinavica, 112, 159-164. http://dx.doi.org/10.1111/j.1600-0463.2004.apm1120301.x

[28] Liakopoulos, A., Mavroidi, A., Katsifas, E.A., Theodosiou, A., Karagouni, A.D., Miriagou, V., et al. (2013) Carbapenemase-Producing Pseudomonas aeruginosa from Central Greece: Molecular Epidemiology and Genetic Analysis of Class I Integrons. BMC Infectious Diseases, 13, 505. http://dx.doi.org/10.1186/1471-2334-13-505

[29] Bert, F., Branger, C. and Lambert-Zechovsky, N. (2002) Identification of PSE and OXA $\beta$-Lactamase Genes in Pseudomonas aeruginosa Using PCR-Restriction Fragment Length Polymorphism. Journal of Antimicrobial Chemotherapy, 50, 11-18. http://dx.doi.org/10.1093/jac/dkf069

[30] Riccio, M.L., Docquier, J.D., Dell’Amico, E., Luzzaro, F., Amicosante, G. and Rossolini, G.M. (2003) Novel 3- $N$ aminoglycoside Acetyltransferase Gene, aac(3)-Ic, from a Pseudomonas aeruginosa Integron. Antimicrobial Agents and Chemotherapy, 47, 1746-1748. http://dx.doi.org/10.1128/AAC.47.5.1746-1748.2003

[31] Miller, G.H., Sabatelli, F.J., Hare, R.S., Glupczynski, Y., Mackey, P., Shlaes, D., Shimizu, K. and Shaw, K.J. (1997) The Most Frequent Aminoglycoside Resistance Mechanisms-Changes with Time and Geographic Area: A Reflection of Aminoglycoside Usage Patterns. Clinical Infectious Diseases, 24, 46-62.

http://dx.doi.org/10.1093/clinids/24.Supplement_1.S46 
[32] Cameron, F.H., Groot Obbink, D.J., Ackerman, V.P. and Hall, R.M. (1986) Nucleotide Sequence of the AAD(2') Aminoglycoside Adenylyltransferase Determinant aadB. Evolutionary Relationship of This Region with Those Surrounding aadA in R538-1 and Dhfrll in R388. Nucleic Acids Research, 14, 8625-8635.

http://dx.doi.org/10.1093/nar/14.21.8625 